\title{
Vehicular emission inventory of criteria pollutants in Delhi
}

Pramila Goyal', Dhirendra Mishra and Anikender Kumar

\begin{abstract}
The rapid urbanization in Delhi has resulted in a tremendous increase in the number of motor vehicles with the increase in population and urban mobilization. The vehicular traffic is now recognized as one of the main sources of air pollution in Delhi and has noticeable impact on air quality. The emission of criteria pollutants namely Carbon Monoxide (CO), Nitrogen Oxide $\left(\mathrm{NO}_{x}\right)$ and Particulate Matter (PM) due to vehicles is estimated through the International Vehicle Emission (IVE) model, which includes the different driving modes of vehicles and meteorological parameters. The estimated emissions of Carbon Monoxide (CO), Nitrogen Oxides $\left(\mathrm{NO}_{x}\right)$ and Particulate Matter (PM) due to different types of vehicles in the year 2008-09 are found to be 509, 194 and 15 tons/day respectively. The diurnal variation of emissions of air pollutants shows two peaks, which are fortunately matching with the morning and evening office hours. The emissions of $\mathrm{CO}$ and $\mathrm{NO}_{x}$ due to personal cars (PCs) are found to be about 34\% and 50\% respectively, and the emission of $\mathrm{CO}$ due to $2 \mathrm{~W}$ (2- Wheeler) is about 61\%. Similarly, the Heavy Commercial Vehicles (HCVs) are contributing PM about $92 \%$. The analysis of fuel-wise emission of pollutants reveals that CO is mainly contributed by petrol, and NOx and PM are contributed by diesel. It is also noticeable that $\mathrm{CO}, \mathrm{NO}_{x}$ and PM emissions at ITO, one of the busiest traffic intersections of Delhi, are approximately 15,6 and 0.5 tons/day respectively, which are found to be the maximum followed by Kashmiri Gate (ISBT), Nizamuddin etc. The present vehicular emissions inventory has been compared quantitatively with previous studies of Delhi. The present vehicular emission inventory has also validated using US environmental protection agency's (USEPA's) AERMOD model with observed concentration at different locations in Delhi. However, the present study shows that the air quality of Delhi has been degraded due to high level emissions of criteria pollutants.
\end{abstract}

Keywords: Vehicular emission, IVE model, Pollutants, Delhi

\section{Introduction}

Delhi is spread over an area of $1,484 \mathrm{~km}^{2}$ (573 sq mi), of which $783 \mathrm{~km}^{2}$ (302 sq mi) is designated rural and $700 \mathrm{~km}^{2}$ (270 sq mi) urban. The city's population is increasing rapidly with a consequent increase in the number of vehicles without a commensurate increase in road length. The number of vehicles registered in Delhi has already crossed 6 million and a sizeable vehicular traffic joins Delhi roads from the neighboring states (DSH 2010). It has been observed that vehicles alone contribute about $64 \%$ of the pollution in Delhi while other sources like power plants, industries, and domestic contribute $16 \%$, $12 \%$ and $8 \%$ respectively (MoEF 1997). The maximum contribution of air pollution is growing rapidly from

\footnotetext{
* Correspondence: pramila@cas.iitd.ernet.in

Centre for Atmospheric Sciences, Indian Institute of Technology Delhi, Hauz Khas, New Delhi 110016, India
}

vehicular sources (Mitra and Sharma 2002). The main air pollutants emitted from these sources are Carbon monoxide (CO), Oxides of nitrogen (NOx) and Particulate Matter (PM). Some of them have been found to be much beyond the permissible levels governed by the Central Pollution Control Board (CPCB). The increasing levels of air pollutants are responsible for higher incidence rate of respiratory diseases, cancer, and heart diseases (Peters et al. 1997). Delhi's degraded air quality is held responsible for about 18,600 premature deaths per year (TERI 2001).

The number of vehicles per kilometer of road in Delhi has gone up from 128 to 191 between 2003 and 2009. This, despite the fact that the total available road space has increased from 30,698 lane kilometers in 2003 to 31,373 lane kilometer in 2009. The vehicle population growth in Delhi is sharply increased by an average annual rate $7.40 \%$ for private vehicles and $9.15 \%$ for

\section{Springer}


commercial vehicles causing severe transportation and environmental problems (GNCTD 2010). It has been found that irrespective of road classes, about $30 \%$ of time, vehicles travel below $20 \mathrm{~km} / \mathrm{h}$ speed. However, Delhi is at the position of the world's $5^{\text {th }}$ worst city in traffic jam point of view (The Economic Times 2010). According to DSH (2010) report, the year wise vehicles growths are shown below in Figure 1.

There are several models used for estimation of vehicular emissions. The USEPA MOBILE model is one of them, which has been widely used. But in this model, the emission factors are conventionally based on the model years of US vehicle type and they are tested only on U.S. fuels and driving cycles, which can lead to incorrect emission values in India. So this model cannot be used for Delhi. One another vehicular emission model COPERT, which is widely used throughout Europe. However, this model cannot be used in Delhi as the emission factors used in this model are designed to be applied to average speeds for different road types. There are many more emission models such as LEAP (Long-range Energy Alternative Planning), VAPIS (Vehicle Air Pollution Information System) and Spreadsheet etc. But these models do not consider the variations in the local environment such as driving behaviors and traffic management and also assume that lower vehicle speeds increase emissions. In view of the above discussion, IVE model has been chosen for emission estimations. This model has been applied in several cities worldwide including Beijing and Shanghai, China (Nicole et al. 2005). The basic features of IVE model are based on (1) different modes of driving; (2) meteorological variables; and
(3) emission factors of different pollutants with respect to different fueled vehicles.

The vehicle and fuel systems have to be addressed as a whole and jointly optimized in order to achieve significant reduction in emission. It was in 1996, the Ministry of Environment and Forests (MoEF), India, formally notified fuel specifications. In place of phase-wise upgradation of fuel specifications, there appears to be a region-wise introduction of fuels of particular specifications. The high levels of pollution have necessitated eliminating leaded petrol throughout the country. To address the high pollution in 4 metro cities, $0.05 \%$ low sulfur diesel has been introduced since 2000-2001.

\section{Methodology}

An emission inventory of main criteria pollutants $\mathrm{CO}$, $\mathrm{NO}_{\mathrm{x}}$ and PM due to vehicles in the year 2008-09 over the central part of Delhi has been developed as follows:

(i) A domain of the study area $26 \mathrm{~km} \times 30 \mathrm{~km}$ $\left(\sim 780 \mathrm{~km}^{2}\right.$ area) in central Delhi has been selected.

(ii) The numbers of vehicles monitored by Central Road Research Institute (CRRI) at 27 locations on different types of roads in the year 2008-09 has been used. It is noticeable that during the monitoring hours, there were no unusual conditions such as major processions, VIP visits, or other activities, which could induce abnormal traffic characteristics in the selected grids during the survey.

(iii) The diurnal variations of vehicular movement are observed at major traffic intersections.

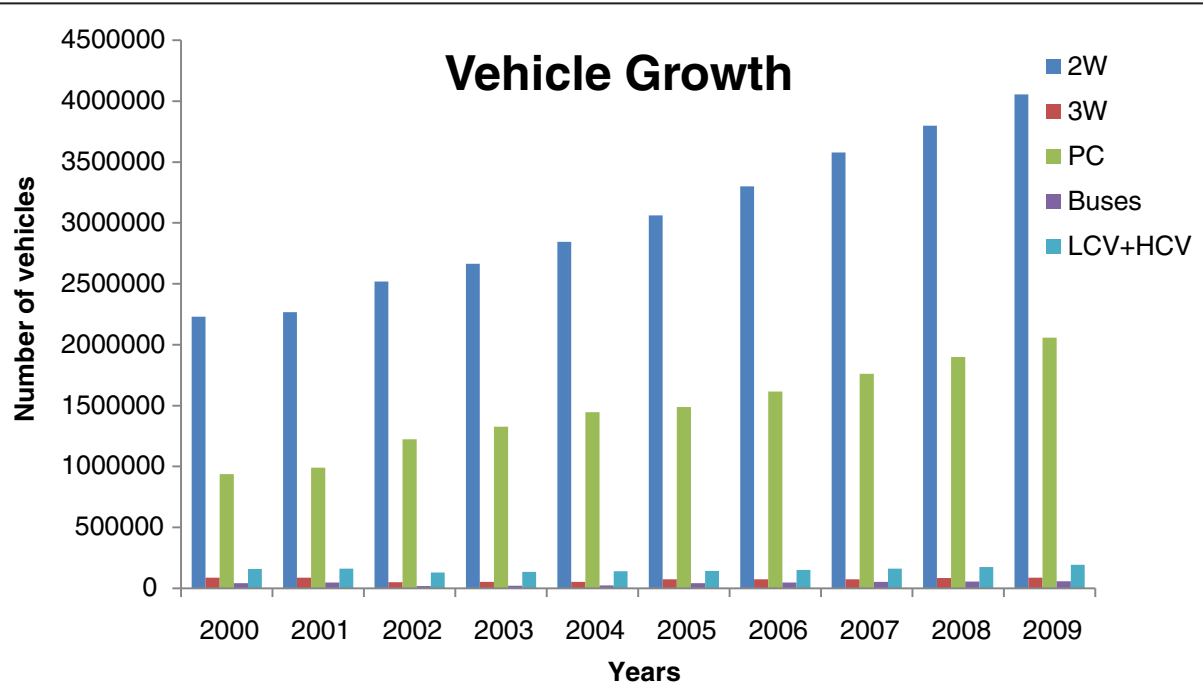

Figure 1 Vehicle growth of Delhi. 
(iv) An emission inventory of each type of vehicle with respect to $\mathrm{CO}, \mathrm{NOx}$ and $\mathrm{PM}$ has been made individually.

(v) The diurnal variations of emissions during a study of start-up and running modes of different fueled vehicles have been estimated through IVE model.

The study area made over the map of Delhi has been shown in Figure 2, which has been divided into 195 grids of $2 \mathrm{~km} \times 2 \mathrm{~km}$ size. IVE model is used to estimate the emissions due to vehicles in each grid of the study area. The monitoring stations of CRRI and CPCB over Delhi are also shown in Figure 2.

The input data of the model is prepared according to the format of the model, which are fleeting characteristics, vehicular activity and emission factors based on local conditions. A fleet file contains the base emission factor adjustment by technology and pollutants. The basis of the emission prediction process of the IVE model begins with a base emission rate and a series of correction factors, which are applied to estimate the amount of pollutants from a variety of vehicle types. On-road fleet characteristics are one of the important factors to estimate emissions. A vehicle activity files mainly requires the information of location/time, temperature, road grade, gasoline information, diesel information and driving pattern distribution. While vehicle emission rate files contain the information of base emission factor and correction factors. There are three critical components that are used in the IVE model to create accurate emissions inventories: (1) Vehicle emission rates (Base Emission Factor and Correction Factors); (2) Vehicle activity (Location Input Data); and (3) Vehicle.

The basis of the emission prediction process of the IVE model is to apply a base emission rate with a series of correction factors to estimate the amount of pollution

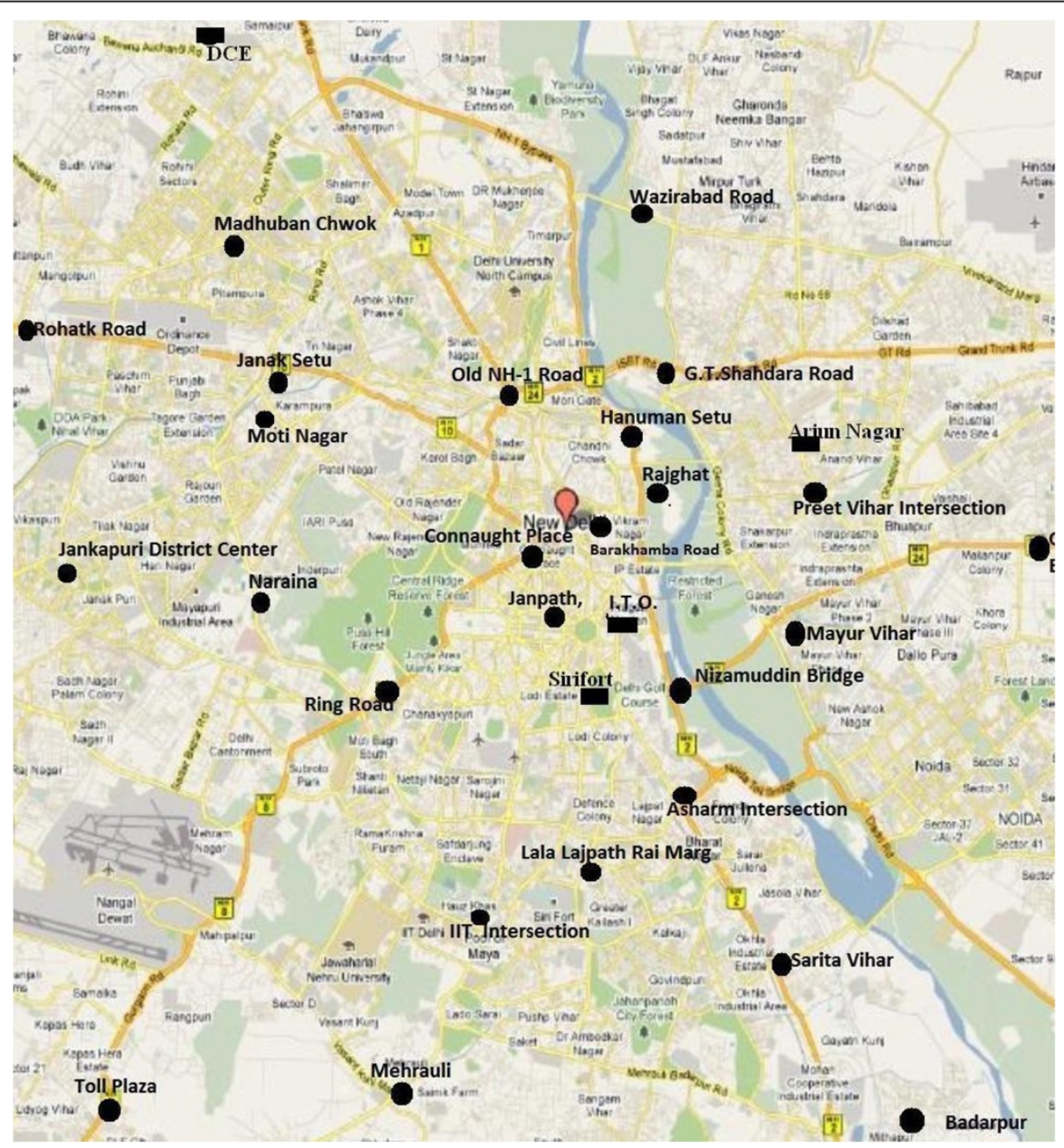

Figure 2 Delhi study area (CRRI monitored station $(\bullet)$ and CPCB monitoring station $(\square)$ ). (Source- www.mapmyindia.com). 
Table 1 Emissions (tons/day) from each type of vehicle

\begin{tabular}{cccc}
\hline Fleet & CO & $\mathbf{N O}_{\mathbf{x}}$ & PM \\
\hline $2 \mathrm{~W}$ & 311.2 & 5.8 & 0.40 \\
$3 \mathrm{~W}$ & 14.4 & 34.5 & 0.01 \\
$\mathrm{PC}$ & 173.5 & 98.2 & 0.12 \\
Bus & 4.5 & 11.8 & 0.01 \\
LCV & 6.7 & 3.2 & 0.60 \\
HCV & 3.26 & 40.2 & 13.48 \\
Total & 509.6 & 193.7 & 14.62 \\
\hline
\end{tabular}

from a variety of vehicles. Equation (1) estimates the adjusted emission rate by multiplying the basic emission rate by each correction factor.

$$
\begin{aligned}
\mathrm{Q}_{[\mathrm{t}]}=\mathrm{B}_{[\mathrm{t}]} * \mathrm{~K}_{(\text {Base })[\mathrm{t}]} \mathrm{K}_{(\mathrm{Tmp})[\mathrm{t}]} \mathrm{K}_{(\text {Hmd })[\mathrm{t}]} * \mathrm{~K}_{(\mathrm{IM})[\mathrm{t}]} \mathrm{K}_{(\text {Fuel })[\mathrm{t}]} \\
{ }^{*} \mathrm{~K}_{(\text {Alt })[\mathrm{t}]}{ }^{*} \mathrm{~K}_{(\text {Cntry })[\mathrm{t}]} \mathrm{K}_{(\mathrm{d})[\mathrm{t}]}
\end{aligned}
$$

where, $\mathrm{Q}_{[\mathrm{t}]}$ : adjusted emission rate for each technology (start $(\mathrm{g})$ or running $(\mathrm{g} / \mathrm{km}) ; \mathrm{B}_{[\mathrm{t}]}$ : base emission rate for each technology (start $(\mathrm{g})$ or running $(\mathrm{g} / \mathrm{km})$. The correction factors used in equation 1 are categorized into several categories as local, fuel quality and power \& driving variables. The local variables are ambient temperature, ambient humidity and altitude. The fuel quality variables are gasoline and diesel. The power \& driving variables are road grade and air conditioning usage (IVEM, 2008). Equation (1) uses correction factors for eight parameters. Because of the lack of location specific data, an adjustment factor to the base emission rate " $K_{(\text {Base) }[t]}$ " has been taken equal to 1 that is the default value for IVE model and the fuel quality " $K_{(\text {Fuel)[t] }}$ ", inspection/maintenance correction factor " $\mathrm{K}_{(\mathrm{IM})[\mathrm{t}]}$ ", country correction factor " $\mathrm{K}_{(\mathrm{Cntry})[\mathrm{t}]}$ " and driving pattern " $K_{[d t]}$ " correction factor are taken from IVEM BERCF 2008 and IVEM Correction Factor Data 2008. In addition to this, values for temperature " $K_{(\text {Temp) } t]}$ ", humidity "K $K_{(\text {Hmdt) }[t]}$ ", altitude "K$($ Alt)[t]", and base emission rate " $B[t]$ " have been taken from the IVE model dataset (IVEM Correction Factor Data 2008).

A data collection methodology has been designed to collect a large amount of data with the help of the resources typically available in Delhi. The hourly number of vehicles monitored at 27 different locations in Delhi by CRRI, have been collected. The roads are chosen in the representative of residential streets, arterials and freeways.

AERMOD is the new dispersion model, proposed for use in regulatory applications, in the United States. AERMOD is intended to replace the USEPA regulatory model, ISCST3. The U.S. EPA has evaluated AERMOD using several field databases. The AERMOD atmospheric dispersion modelling system is an integrated system that includes-1) A steady-state dispersion model designed for short-range (up to 50 kilometers) dispersion of air pollutant emissions from stationary industrial sources. 2) A meteorological data preprocessor (AERMET) that accepts
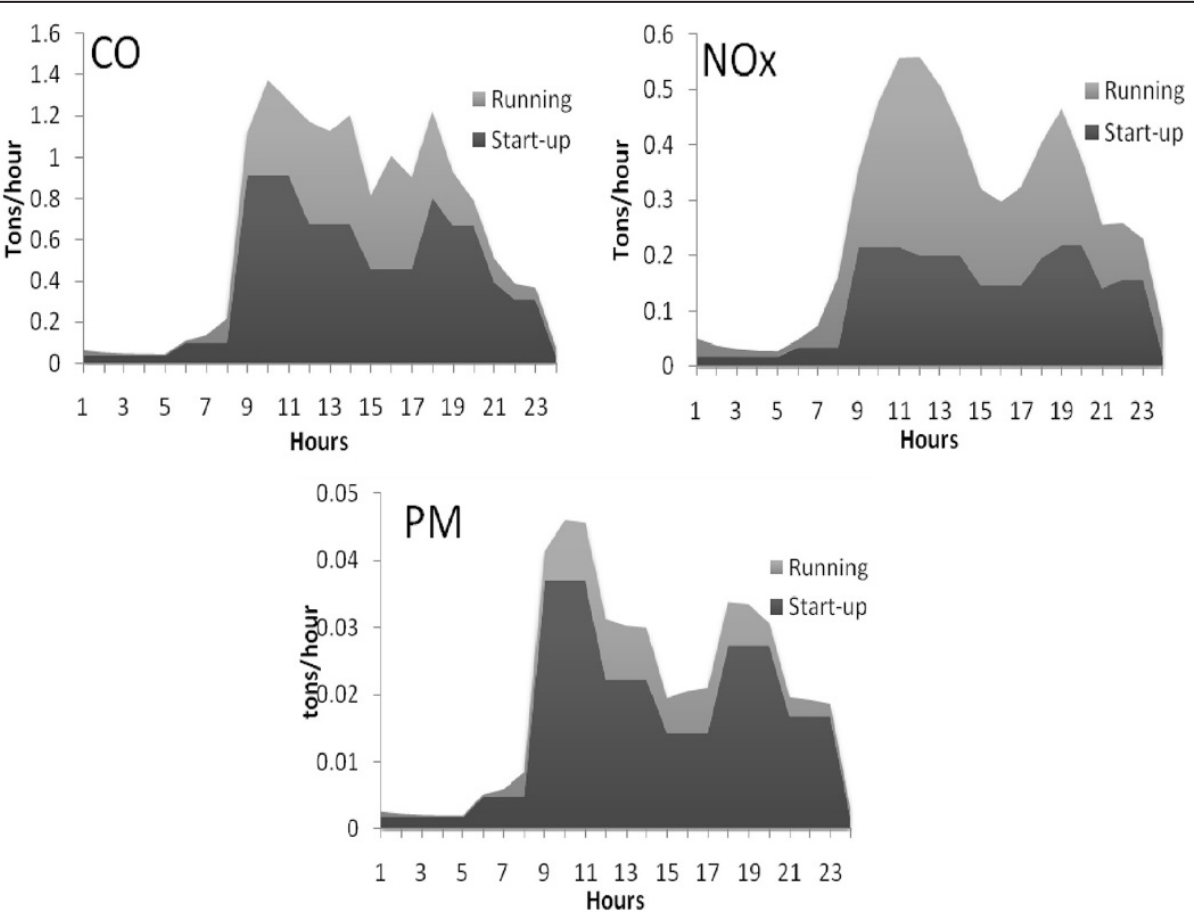

Figure 3 Vehicle daily emission pattern at ITO. 

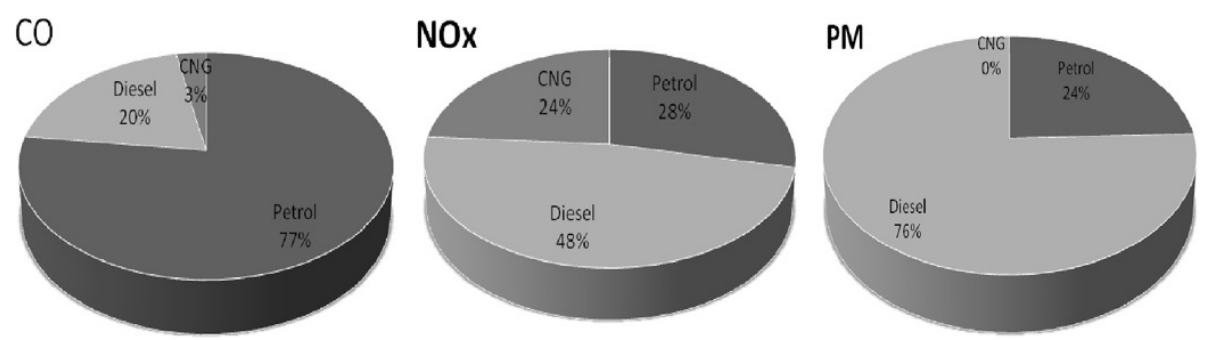

Figure 4 Fuel wise emissions of pollutants from vehicles.

surface meteorological data, upper air soundings, and optionally, data from on-site instrument towers. AERMOD requires hourly surface and upper air meteorological observations for simulating the pollutant dispersion (USEPA 2004). The major purpose of AERMET is to calculate boundary layer parameters for use by AERMOD. The meteorological preprocessor of AERMOD, known as AERMET calculates boundary layer parameters, viz. frictional velocity, Monin-Obukhov length, convective velocity scale, temperature scale, mixing height, surface heat flux by using local surface characteristics in the form of surface roughness and Bowen ratio in combination with standard meteorological observations (wind speed, wind direction, temperature and cloud cover). These parameters are then passed through an interface present in AERMOD to calculate vertical profiles of wind speed, lateral and vertical turbulent fluctuations, and the potential temperature gradient. The hourly surface meteorological observations have been acquired from Indian Meteorological Department (IMD), Delhi and twice daily upper air soundings have been acquired from university of Wyoming's upper air sounding.

\section{Results and discussions}

The total emissions of $\mathrm{CO}, \mathrm{NO}_{\mathrm{x}}$ and $\mathrm{PM}$ from different types of vehicles over the study area of Delhi are found to be approximately 509, 194 and 15 tons/day respectively during the year 2008-09 and are shown in Table 1, which reveals that 2 wheelers $(2 \mathrm{~W})$ and personal cars (PCs) are the mainly emitting the $\mathrm{CO}$ and $\mathrm{NO}_{\mathrm{x}}$ respectively, while heavy commercial vehicles (HCV) are mainly emitting PM.

It is also observed that the emissions of air pollutants at various locations as ITO, Kashmiri Gate (ISBT), Nizamuddin, Shahzada bagh, Sirifort, Shahdara are in decreasing order. The estimated values of emission of CO, NOx, and PM at ITO are as 15, 6 and 0.5 tons/day respectively.

It is noticeable that the emissions of different criteria pollutants are varying differently into the different operating conditions of vehicles, e.g., $\mathrm{CO}$ emissions are found to be higher during idling and decelerating than cruising, the NOx and PM emissions are lower during idling and decelerating than cruising. Therefore, shutting down the engine and restarting it will result in reduced emissions compared to allowing it to idle. Thus, one can say that the longer the shutdown period, the greater the emission benefits.

The diurnal variation of emissions of criteria pollutants CO, NOx and PM at ITO junction are shown in Figure 3. The two emission peaks during the day in each of these plots are evident, which indicate the peak traffic hours i.e., 8:00-10:00 in the morning and 17:00-19:00 in the evening, which are matched with starting and closing hours of most of the offices in Delhi. The emissions of air pollutants at peak traffic hours are $56 \%$ to $62 \%$. This figure also shows the hourly variation of vehicular emissions of different air pollutants in start-up and running modes. The $\mathrm{CO}, \mathrm{NO}_{\mathrm{x}}$ and $\mathrm{PM}$ are emitted $86 \%, 27 \%$ and $71 \%$ respectively in start-up mode. The peaks of start-up

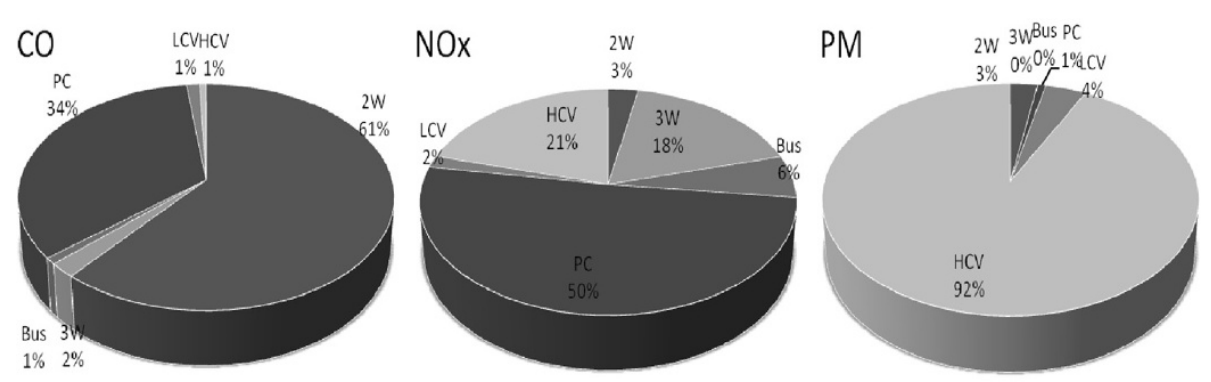

Figure 5 Vehicle-wise emissions of criteria pollutants. 
Table 2 Comparative analysis of vehicular emissions (tons/day) from different studies

\begin{tabular}{|c|c|c|c|}
\hline Studies (Place-fuel) & $\mathrm{CO}$ & $\mathrm{NO}_{\mathrm{x}}$ & PM \\
\hline Kansal et al. 2011 (ITO- all fuel) for year 2004-05 & - & 0.74 & 2.89 \\
\hline IIT study (ITO- all fuel) for the years 2008-09 & 14.89 & 5.87 & 0.49 \\
\hline $\begin{array}{c}\text { Nagpure et al. } 2011 \text { (Delhi- petrol) for average } \\
\text { values of years 1995-2005 }\end{array}$ & 216.45 & 9.85 & - \\
\hline IIT study (Delhi- petrol) for the year 2008-09 & 397.75 & 54.90 & 0.46 \\
\hline $\begin{array}{c}\text { Gurjar et al. } 2004 \text { (Delhi- all fuel) for the } \\
\text { year } 2000\end{array}$ & 1210.47 & 363.98 & 76.52 \\
\hline IIT study (Delhi- all fuel) for the year 2008-09 & 509.62 & 193.46 & 14.59 \\
\hline
\end{tabular}

emissions always appear between 8:00 am and 10:00 am, which is consistent with morning vehicle starts, and more than half of the starts are cold starts. (At start-up, especially during cold start, the temperature in the engine is low and fuel condensation is formed on the inner surface of the cylinder causing it to operate in the rich mode (high fuel-to-air ratio). This results in incomplete combustion of the fuel). Also, the catalysts are not operating when the temperature is not conductive to $\mathrm{NOx}$ formation. Therefore, the proportion of NOx emission is not as large as the other pollutants of vehicular emissions and the PM emission is always less than $\mathrm{CO}$ and NOx emissions.

The vehicle and fuel systems have to be addressed as a whole and jointly optimized in order to achieve significant reduction in emission. It was in 1996, the Ministry of Environment and Forests (MoEF), India formally notified fuel specifications. In place of phase-wise up-gradation of fuel specifications, there appears to be a region-wise introduction of fuels of particular specifications. The high levels of pollution have necessitated eliminating leaded petrol throughout the country. In order to address the high pollution in 4 metro cities, $0.05 \%$ sulfur petrol and CNG have been introduced since 2000-01 in place of diesel. After replacement of most diesel vehicles with CNG, the fuel wise emissions of air pollutants during the year 2008-09 are shown in Figure 4. The petrol, diesel
Table 4 Comparison of emissions between Nagpure et al. 2011 and IIT study for the year 1995-2005

\begin{tabular}{cccc}
\hline Pollutants & $\begin{array}{c}\text { Nagpure et al. 2011 for } \\
\text { the average values of } \\
\text { emissions of 1995-2005 }\end{array}$ & $\begin{array}{c}\text { IIT study for the } \\
\text { average values of } \\
\text { emissions of } \\
\mathbf{1 9 9 5}-\mathbf{2 0 0 5}\end{array}$ & $\begin{array}{c}\% \\
\text { difference }\end{array}$ \\
\hline $\mathrm{CO}$ & $593 \mathrm{~kg} /$ year & $652.67 \mathrm{~kg} / \mathrm{year}$ & $10.06 \%$ \\
$\mathrm{NO}_{\mathrm{x}}$ & $27 \mathrm{~kg} / \mathrm{year}$ & $20.38 \mathrm{~kg} / \mathrm{year}$ & $24.44 \%$ \\
\hline
\end{tabular}

and CNG vehicles emit $\mathrm{CO}$ as $77 \%, 20 \%$ and $3 \%$, and NOx as $28 \%, 48 \%$ and $24 \%$ respectively. The diesel, petrol and CNG vehicles emit PM as 76\%, 24\% and 0\% (negligible) respectively. On the basis of the above results, one can conclude that petrol and diesel vehicles are the main source of $\mathrm{CO}, \mathrm{NO}_{\mathrm{x}}$ and PM.

The above discussion has also been supported by the vehicle-wise emission of air pollutants in Figure 5, which reveals that $\mathrm{CO}$ is contributed $61 \%$ by $2 \mathrm{~W}$ and $34 \%$ by PCs. It is obvious as $2 \mathrm{~W}$ are running on petrol. Similarly, the NOx is contributed $50 \%$ by PCs, which is in second position in most frequently running category of vehicles. Hence, in general $2 \mathrm{~W}$ and PCs are considered to be the main contributor of air pollutants in Delhi. However, 3 wheelers (3W) and buses are contributing very small or negligible amount of PM, since the CNG is used compressed natural gas in most of these vehicles.

\section{Evaluation of present estimated emissions}

In general, it is always found to be difficult to evaluate the estimated emissions of air pollutants, since the real data on emissions are not available. However, in the present study (IIT study), the vehicular emissions of air pollutants are evaluated by comparing them with the estimated emissions of three previous studies by Kansal et al. (2011), Nagpure et al. (2011) and Gurjar et al. (2004) in Table 2, which shows a remarkable difference between the emissions of different studies. The first reason of this difference might be due to the consideration of the number of vehicles of different years and the second might be the use of different emission factors.

Table 3 Comparison of emissions between Kansal et al. 2011 and IIT study for the year 2004-05

\begin{tabular}{|c|c|c|c|c|c|c|}
\hline \multirow[t]{2}{*}{ Locations } & \multicolumn{3}{|c|}{$\mathrm{NO}_{\mathrm{x}}$ Emissions (g/sec) } & \multicolumn{3}{|c|}{ PM Emissions (g/sec) } \\
\hline & $\begin{array}{l}\text { Kansal et al. } 2011 \text { study for } \\
\text { the year } 2004-05\end{array}$ & $\begin{array}{l}\text { IIT study for the } \\
\text { year 2004-05 }\end{array}$ & $\begin{array}{c}\% \\
\text { change }\end{array}$ & $\begin{array}{l}\text { Kansal et al. } 2011 \text { study for } \\
\text { the year 2004-05 }\end{array}$ & $\begin{array}{l}\text { IIT study for the } \\
\text { year 2004-05 }\end{array}$ & $\begin{array}{c}\% \\
\text { change }\end{array}$ \\
\hline ITO & 33.40 & 40.96 & 22.63 & 8.60 & 10.95 & 27.27 \\
\hline Shazadabad & 8.80 & 11.06 & 25.68 & 2.60 & 3.65 & 35.55 \\
\hline Janakpuri & 6.40 & 8.52 & 30.00 & 2.60 & 3.34 & 28.39 \\
\hline Ashok Vihar & 2.50 & 3.20 & 28.00 & 2.10 & 2.54 & 20.96 \\
\hline Shahdara & 24.40 & 26.26 & 7.63 & 7.60 & 8.25 & 8.50 \\
\hline Sirifort & 21.90 & 25.60 & 16.89 & 7.70 & 8.35 & 8.47 \\
\hline Nizamuddin & 14.10 & 14.27 & 1.23 & 6.70 & 8.39 & 25.25 \\
\hline
\end{tabular}


Table 5 Comparison of emissions between Gurjar et al. 2004 and IIT study for the year 2000

\begin{tabular}{cccc}
\hline Pollutants & $\begin{array}{c}\text { Gurjar et al. 2004 for } \\
\text { the year } \mathbf{2 0 0 0}\end{array}$ & $\begin{array}{c}\text { IIT study for the } \\
\text { year } \mathbf{2 0 0 0}\end{array}$ & $\begin{array}{c}\% \\
\text { difference }\end{array}$ \\
\hline $\mathrm{CO}$ & 1210.47 tons/day & 1054.83 tons/day & $12.86 \%$ \\
$\mathrm{NO}_{\mathrm{x}}$ & 363.98 tons/day & 385.45 tons/day & $5.89 \%$ \\
$\mathrm{PM}$ & 76.52 tons/day & 89.68 tons/day & $17.19 \%$ \\
\hline
\end{tabular}

The "IIT study" estimated the emissions of CO, NOx and PM due to all different fueled (petrol, diesel and CNG) vehicles over study area of Delhi for the year 2008-09 and emission factors by ARAI (2007). Kansal et al. (2011) studied emissions of NOx and PM at different locations due to all fueled vehicles for the year 2004-05 with the emission factor of Kandilkar and Ramachandran (2000). Nagpure et al. (2011) studied emissions of $\mathrm{CO}$ and NOx over Delhi due to petrol vehicles for the years 1995-2005 excluding 2 wheelers. Gurjar et al. (2004) estimated the emissions of the same pollutants due to different fueled vehicles for the year 2000 using emission factors of Kandilkar and Ramachandran (2000).

Kansal et al. (2011) estimated emissions by using number of all fueled vehicles of the year 2000-01 and emission factors of the study of Kandilkar and Ramachandran (2000), which are different than those used in the IIT study. The IIT study has used the number of all fueled vehicles of the year 2008-09 and emission factors by ARAI (2007) for estimating the emissions of $\mathrm{CO}, \mathrm{NO}_{\mathrm{x}}$ and PM. In order to make the comparison between two of the same year's vehicles and emission factor, the IIT study has been made using the number of vehicles and emission factors for the year 2004-05. The emissions estimated by both the studies for $\mathrm{NO}_{\mathrm{x}}$ and $\mathrm{PM}$ at different locations in Delhi are shown in Table 3, which shows a good agreement between both the emissions at different locations in Delhi.

Similarly the IIT study has been made for the years 19952005. The comparison of average emissions for the same years of both the studies is shown in Table 4, which reflects a very small difference in both the values as $10-25 \%$.

Same methodology has been adopted for comparing the emissions of IIT study and Gurjar et al. (2004). The IIT study estimated the emissions of the year 2000. The corresponding values are compared with the emissions of Gurjar's study and found that the values of emissions of both the studies for all three pollutants are in very good agreement as shown in Table 5. The difference is $6-17 \%$ in both of the studies.

On the basis of the above discussion, it can be seen that emissions of IIT study for different years are very well matching with the emissions of the previous studies. Although, the methods used in all four are different. Finally it can be concluded that estimated emissions by

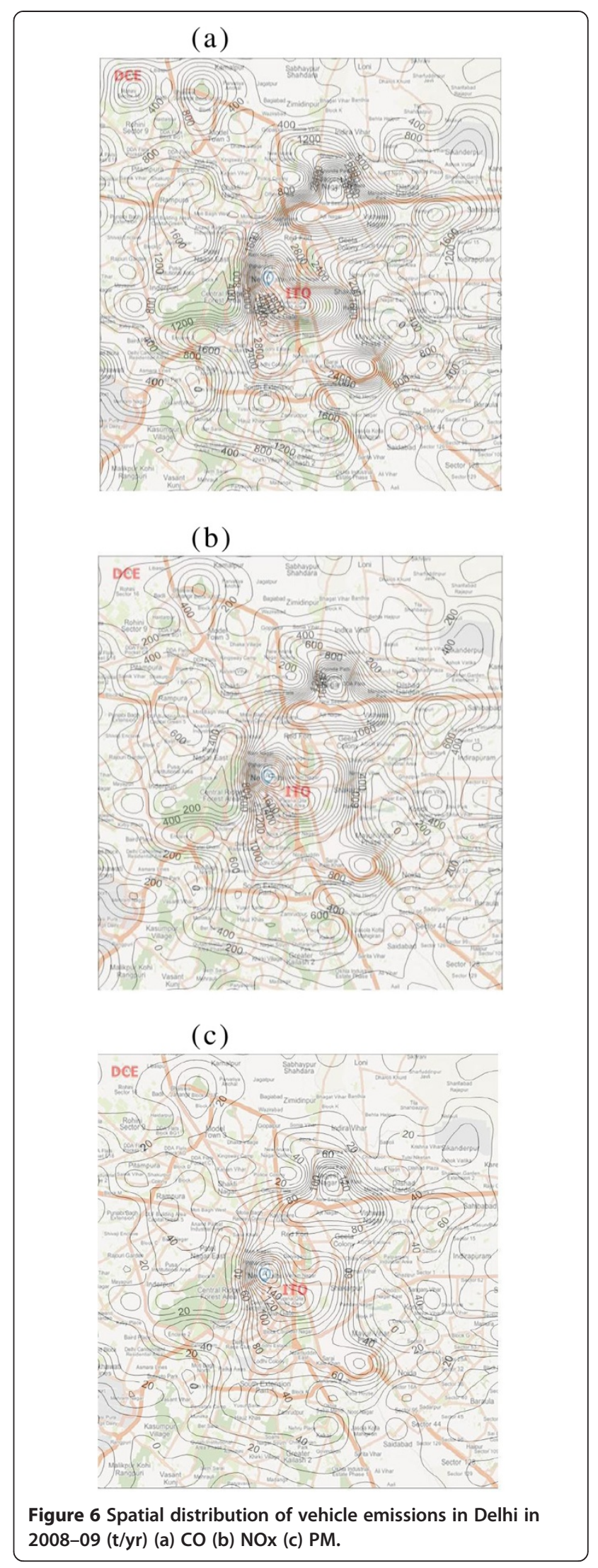


IIT study are validated and can be considered for modeling studies and projection of future emissions. This study can also be used by policy makers and regulatory agencies for making some strategies for controlling the vehicular emissions in Delhi.

\section{Spatial distribution of vehicle emissions}

The spatial $(2 \mathrm{~km} \times 2 \mathrm{~km})$ emission inventories of $\mathrm{CO}$, NOx and PM are shown in Figure 6. It shows that the spatial distributions of annual vehicle emissions. It can be observed that, although the spatial distribution trends of the three pollutants' emissions are similar. The vehicular emission rate of $\mathrm{CO}$ and $\mathrm{NOx}$ are more in comparison to PM emissions. This may be because of the low vehicular emission factor of PM pollutant in comparison to $\mathrm{CO}$ and $\mathrm{NOx}$ pollutants.

\section{Simulation of the pollutant dispersion}

The USEPA's AERMOD model is a well accepted air pollution dispersion model worldwide. Currently, AERMOD is proposed the regulatory models for the Indian conditions. In this study, AERMOD model is adopted to simulate pollutant dispersion caused by motor vehicle emissions.

The dealing with meteorological data in AERMET, upper air data for Delhi cannot be used directly. The upper air data at 0:00 and 12:00 (UTC) switched in order to require by AERMET. The upper air data and surface air data for Delhi are received from the Atmospheric Science Department, University of Wyoming, Laramie, WY.

The modeling results are shown in Figure 7. It is found that the spatial distributions of the three pollutant concentrations are similar with the spatial distributions of their emissions comparing with Figure 6. This is consistent with the fact that vehicular emissions usually affect their surrounding area, without considering the chemical reactions. It can also be observed that the annual concentrations of $\mathrm{CO}$ caused by on-road transportation are considerably high (the highest concentration is above approximately $6834 \mu \mathrm{g} / \mathrm{m}^{3}$ ), while the concentrations of PM caused by vehicular emissions are low (the highest concentration is about approximately $24 \mu \mathrm{gg} / \mathrm{m}^{3}$ ). According to the National Ambient Air Quality Standards (NAAQS) in Delhi, the annual PM concentration standard is $60 \mu \mathrm{g} / \mathrm{m}^{3}$. Considering the annual PM concentration has exceeded the standard for the past several years, it is believed that motor vehicles are not only a major contributor of PM emissions in Delhi. Of course, the accurate estimation of concentration contributions from mobile source depends on the accurate estimation of other source emission inventories, mainly the stationary sources.

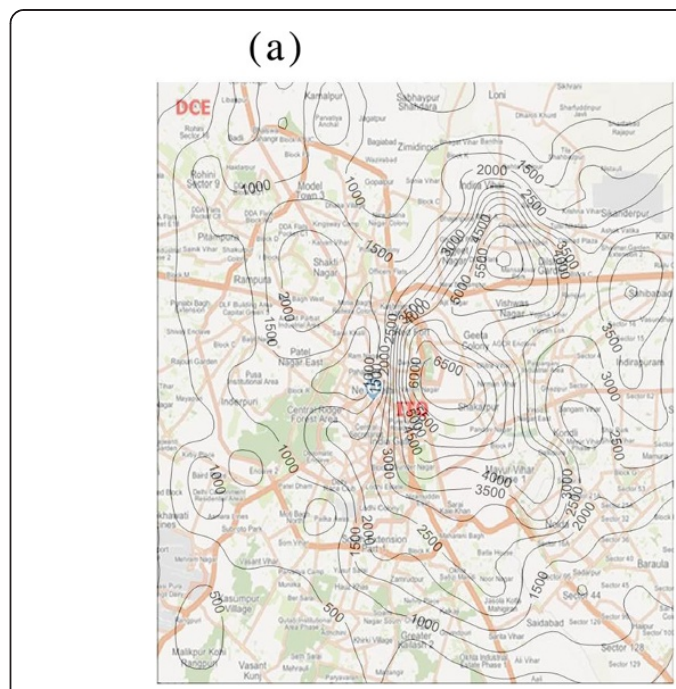

(b)

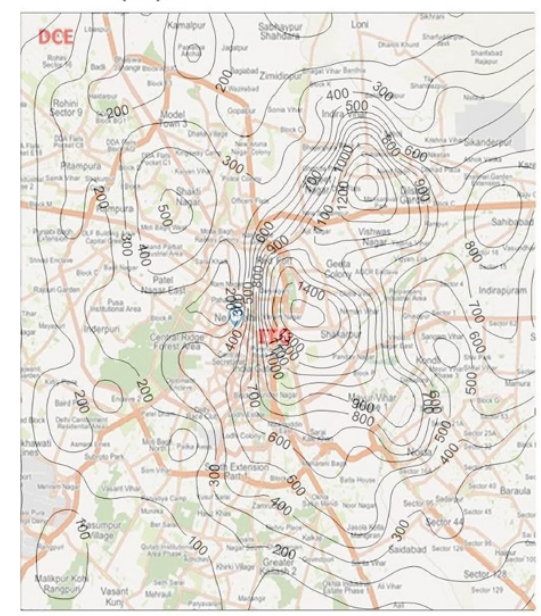

(c)

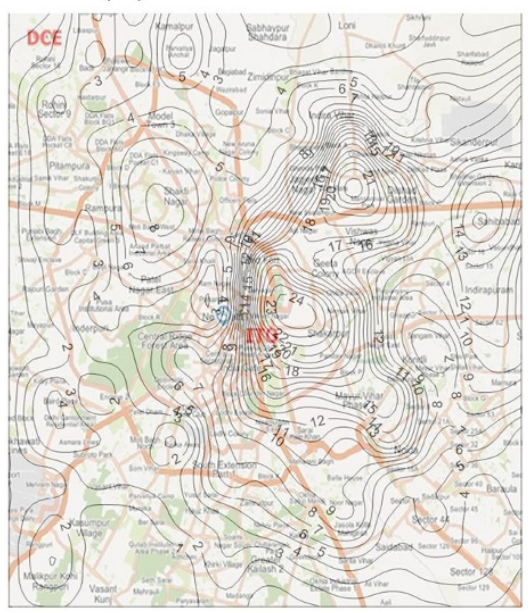

Figure 7 Spatial distribution of annual-averaged emission concentrations caused by the motor vehicles in Delhi in 2008-09 $\left(\mu \mathrm{g} / \mathrm{m}^{3}\right)$ (a) CO (b) NOx (c) PM. 

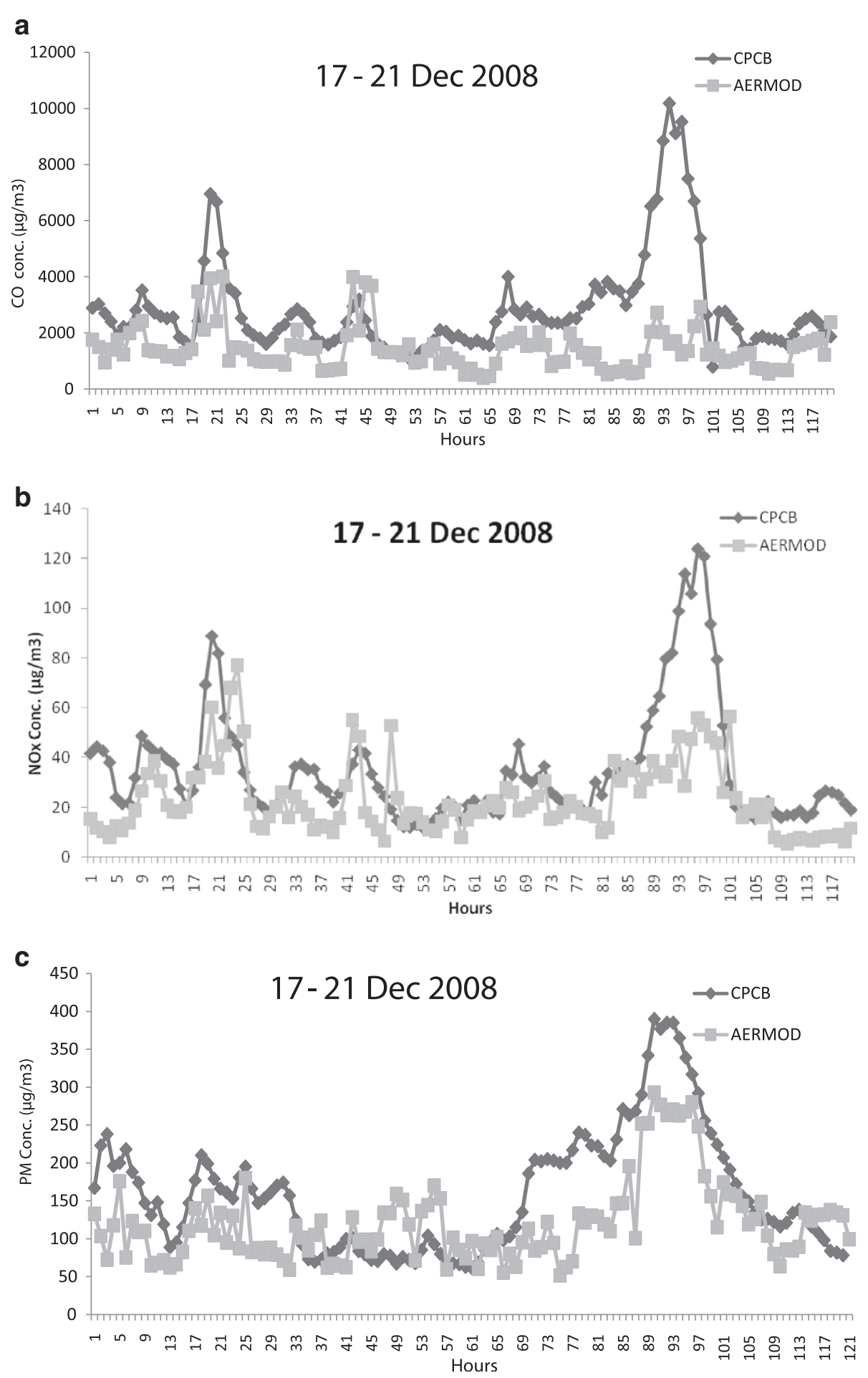

Figure 8 Hourly variations of concentrations caused by the motor vehicles at ITO junction in Delhi during 17-23 December 2008 $\left(\mu \mathrm{g} / \mathrm{m}^{3}\right)$ (a) CO (b) NOx (c) PM. 

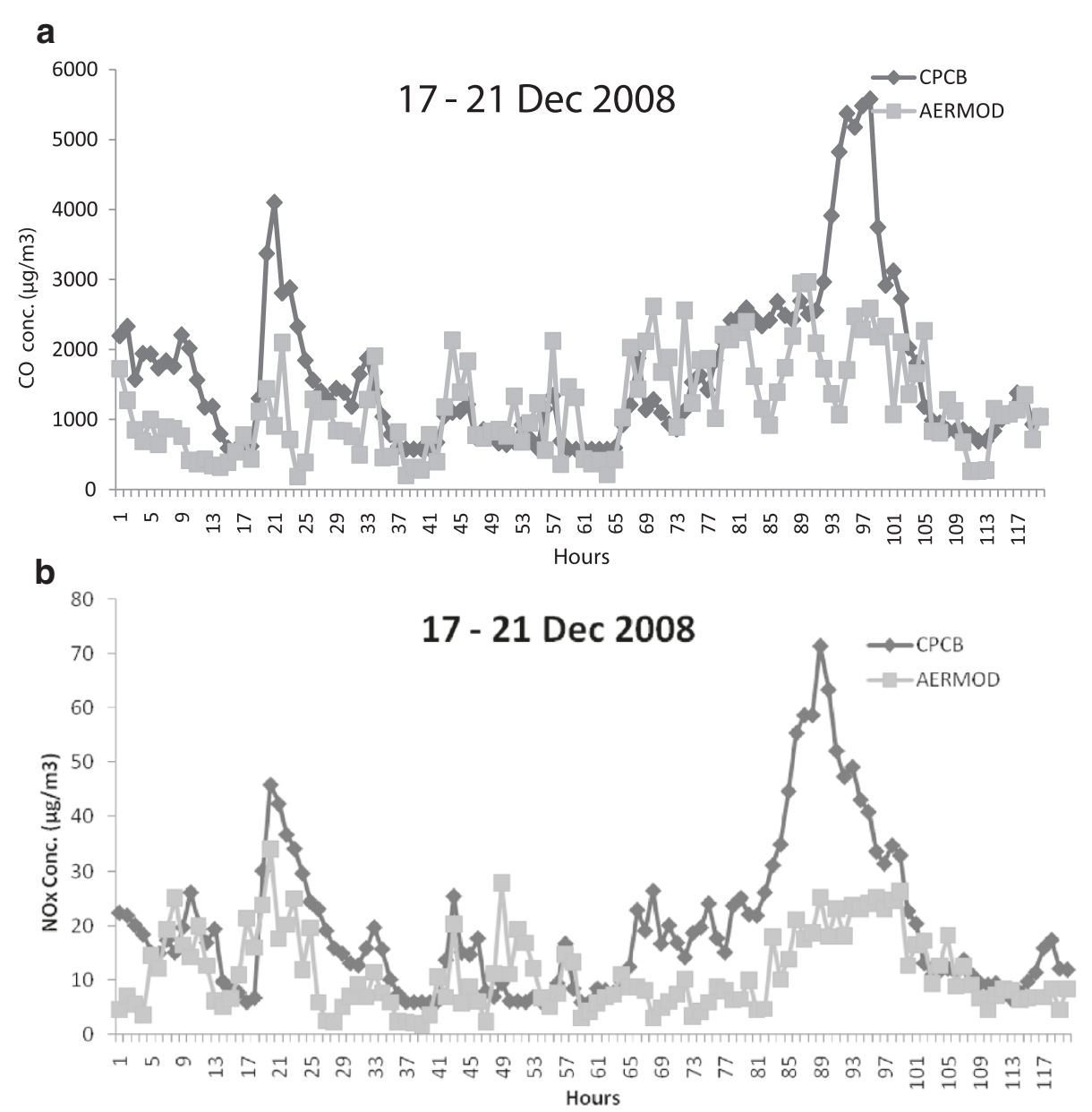

Figure 9 Hourly variations of concentrations caused by the motor vehicles at DCE station in Delhi during 17-23 December 2008 $\left(\mu \mathrm{g} / \mathrm{m}^{3}\right)$ (a) CO (b) NOx.

\section{Variations of predicted concentrations with observed concentrations}

A comparative analysis of the AERMOD model predicted concentrations using the prepared emission inventory of criteria pollutants CO, NOx and PM against the observed concentration of that pollutant continuously monitored at ITO junction and DCE station. The winter month, December in the year 2008 has been chosen for the comparison of predicted with observed concentrations at both stations in Delhi. For the present study, 5 days have been chosen for representative month, December of the winter season to check the consistency of the concentrations with AERMOD. The dates chosen for the analysis are $17^{\text {th }}$ to $21^{\text {st }}$ December 2008. AERMOD has been executed to obtain the hourly $\mathrm{CO}, \mathrm{NOx}$ and PM concentrations at ITO junction and then compared with the observed. Similarly the comparison of $\mathrm{CO}$ and NOx predicted concentrations from motor vehicles with the observed concentrations at DCE station also. Hourly variations of 5 days concentrations for Dec, 2008 at ITO junction and DCE station are shown in Figures 8 and 9 respectively. It is observed that the predicted concentrations of these criteria pollutants from motor vehicles are in good agreement with the observed concentrations from all sources. It is noticeable that the predicted concentrations of motor vehicles are approximately every hour lower than the observed concentrations of all sources at both stations in Delhi. It is also observed that the motor vehicle emissions are the main contributor in the observed concentrations of criteria pollutants. Again, the predicted concentrations of motor vehicles are positively correlated with the observed concentrations at ITO e.g. the values correlation coefficient for CO, NOx and PM pollutants are observed 0.33, 0.63 and 0.39 respectively. Similarly, the values of correlation coefficients for $\mathrm{CO}$ and NOx pollutants at DCE stations are 0.50 and 0.57 respectively.

\section{Conclusions}

This paper develops vehicle emission inventory for Delhi, the capital of India, using for detailed study of 
emissions from vehicular sources. The purpose of this paper is to introduce a new grid based mobile source emission inventory using IVE model. The vehicle emissions of CO, NOx and PM are approximately 509, 194 and 15 tons per day respectively, in Delhi for the year 2008-09. The maximum emissions approximately $86 \%$, $27 \%$ and $71 \%$ of the total emissions are emitted during the starting-up period for $\mathrm{CO}, \mathrm{NO}_{\mathrm{x}}$ and $\mathrm{PM}$ respectively. Petrol and diesel fuel vehicles are the main source of $\mathrm{CO}$ and PM pollutants respectively. CNG vehicles are one of the main contributors in $\mathrm{NO}_{\mathrm{X}}$ emission. The emissions of the present study are evaluated with those of previous studies made by Kansal et al. (2011), Nagpure et al. (2011) and Gurjar et al. (2004), which reveals that the results of the present study are quite satisfactory and agreed well with previous studies. The spatial and temporal emission inventories of criteria pollutants from on-road vehicle emissions are justified with AERMOD analysis. The IIT emission inventory is superior to previous studies in the following manner as these three studies are based on number of vehicles, emission factor and vehicle kilometer travel. The IIT study calculates the emissions using IVE model, which also includes (1) different modes of driving; (2) meteorological variables in terms of correction factor; and (3) emission factors of different pollutants with respect to different type and fueled vehicles. However, the IIT emissions are seems to be comparable with earlier studies and are also validated through air quality model.

There are some drawbacks in the present emission inventory as the emission values of the present study would be improved if hourly monitored values of the number of all different types and different fueled vehicles at each grid point, i.e., at each $2 \mathrm{~km}$ distance would be available. The major uncertainty of the present study is the use of piecewise information concerning the emissions.

\section{Competing interests}

The authors competing interests are air pollution modelling, air quality forecasting techniques, carrying/assimilative capacity of air environment, preparation of source inventories and enviornemntal impact assessment studies.

\section{Authors' contributions}

PG participated in the design of the study and participated in the preparation of the manuscript. DM and AK prepared the emission rates of pollutants, evaluated with observed data and prepared the manuscript. All authors have read and approved the final manuscript.

Received: 28 February 2013 Accepted: 20 April 2013

Published: 10 May 2013

\section{References}

ARAI (The Automotive Research Association of India) (2007) Air Quality

Monitoring Project-Indian Clean Air Programme (ICAP), Draft Report on

"Emission Factor Development for Indian Vehicles" as a part of ambient air quality monitoring and emission source apportionment studies
DSH (Delhi Statistical Handbook) (2010) Directorate of Economics \& Statistics, Government of National Capital Territory of Delhi, various issues. http://www. delhi.gov.in/. Accessed on October 2010

GNCTD (2010) State of Environment Report for Delhi, Department of Environment and Forests. Government of NCT of Delhi, New Delhi, India

Gurjar BR, Van Aardenne JA, Lelieveld J, Mohan M (2004) Emission estimates and trends (1990-2000) for megacity Delhi and implications. Atmos Environ 38:5663-5681

IVEM (2008) International vehicular emission model, development of the emission rates for use in the IVE Model. http://www.issrc.org/ive/. Jan. 23, 2009

IVEM BERCF (2008) IVEM Base Emission Rate Correction Factor Data, Appendix B: Correction Factor Data (.xls). http://www.issrc.org/ive. (Jan. 23, 2009)

IVEM Correction Factor Data (2008) Appendix B: Correction Factor Data (.x|s). http://www.issrc.org/ive. (Jan. 23, 2009)

Kandilkar M, Ramachandran G (2000) The causes and consequence of particulate air pollution in urban: A Synthesis of the Science. Annu Rev Energy Env 25:629-684

Kansal A, Khare M, Sharma CS (2011) Air quality modelling study to analyse the impact of the World Bank emission guidelines for thermal power plants in Delhi. Atmos Pollut Res 2:99-105

Mitra AP, Sharma C (2002) Indian aerosols: present status. Chemosphere 49:1175-1190

MoEF (1997) White paper on pollution in Delhi with an action plan. Ministry of Environment and Forest, Government of India, New Delhi

Nagpure AS, Gurjar BR, Kumar P (2011) Impact of altitude on emission rates of ozone precursors from gasoline-driven light-duty commercial vehicles. Atmos Environ 45:1-5

Nicole D, James L, Mauricio O, Nick N, Matthew B (2005) Transportation Research Board 81st Annual Meeting, Washington DC

Peters A, Wichmann HE, Tuch T, Heinrich J, Heyder J (1997) Respiratory effects are associated with the number of ultrafine particles. Am J Respir Crit Care Med 155:1376-1383

TERI (2001) TERI Project Report No. 2001EE41. Tata Energy Research Institute, New Delhi

The Economic Times (2010) Delhi world's fifth worst city for commuters: Study USEPA (2004) AERMOD: description of model formulation. Report EPA-454/R-0304. September 2004. http://www.epa.gov/scram001/7thconf/aermod/ aermod_mfd.pdf

doi:10.1186/2193-1801-2-216

Cite this article as: Goyal et al:: Vehicular emission inventory of criteria pollutants in Delhi. SpringerPlus 2013 2:216.

\section{Submit your manuscript to a SpringerOpen ${ }^{\odot}$ journal and benefit from: \\ - Convenient online submission \\ Rigorous peer review \\ - Immediate publication on acceptance \\ - Open access: articles freely available online \\ - High visibility within the field \\ - Retaining the copyright to your article}

Submit your next manuscript at springeropen.com 